\title{
Critical factors for achieving multiple goals with water tariff systems: Combining limited data sources and expert testimony
}

\author{
Jasper Dalhuisen and Peter Nijkamp \\ Department of Spatial Economics, Free University and Tinbergen Institute, Amsterdam, Netherlands
}

Received 6 August 2001; revised 17 December 2001; accepted 17 December 2001; published 4 July 2002.

[1] Price instruments are well-known policy handles to influence effectively residential water demand. Prices used to be set by water authorities in such a way that the principle of cost coverage was respected; they acted as prominent instruments in residential water policies in the past decades. More recently, however, price instruments are increasingly used to meet simultaneously financial, environmental, and social goals. This paper addresses four conditions for an appropriate tariff system for residential water use which are often found in the recent literature on the economics of water use. The paper analyzes the importance of background factors (e.g., low water availability) of these four principles as well as the extent to which actual tariff systems are employed in five mutually contrasting cities (Amsterdam, Athens, London, Seville, and Tel Aviv). Metaanalytic techniques, in particular, rough set analysis stemming from artificial intelligence, are applied to identify the common underlying relations between background factors and success of achieving multiple goals in these five urban case studies. The paper concludes with policy recommendations. INDEX TERMS: 6339 Policy Sciences: System design; 6319 Policy Sciences: Institutions; 6344 Policy Sciences: System operation and management; 9335 Information Related to Geographic Region: Europe; KEYWORDS: water pricing, rough set analysis, water use, tariff systems

\section{Water as an Economic Good}

[2] Water scarcity is a predominant resource problem in many parts of the world and is often viewed as a shortage of water (which can be considered as the quantitative dimension of water). However, there are two other concerns: a shortage of water of a minimum quality to carry out important usage functions such as drinking water (the qualitative dimension) and protection against an abundance of water, for example, flooding [see de Haas et al., 2000].

[3] Solutions to water scarcity problems were in the past decades, in general, technically oriented. Economic incentives did not obtain a prevalent role. Public authorities or managers of water companies used tariff systems for water use mainly for the purpose to cover (part of) the costs of the water production, investments, and transportation process. There is, however, a contrary development in the recent past; we witness that a number of Organization for Economic Cooperative Development (OECD) countries increasingly uses water tariffs to reach broader socioeconomic goals, such as increasing the efficiency of water use or achieving social and environmental goals. A tariff that simultaneously meets these multiple goals to the largest possible extent may be considered as an optimal tariff system [OECD, 1998].

[4] The purpose of a tariff system is to influence different water users by varying prices. To measure the effectiveness of water prices, various authors have, for a long period of time, tried to estimate the effect of changes in prices on water demand. These authors have usually estimated price

Copyright 2002 by the American Geophysical Union. 0043-1397/02/2001WR000841\$09.00 elasticities, i.e., the relative change in residential water demand as a response to a relative price change [see, e.g., Baumann et al., 1998]. The main purpose for carrying out such demand studies was the need to get insight into the effectiveness of price instruments. The general results were certainly not unambiguous. The need for systematic insight into variation of consumers to price changes led Espey et al. [1997] to carry out a meta-analysis on 124 estimates of price elasticities based on officially published residential water demand studies. More recently, Dalhuisen et al. [2001] have extended the analysis of Espey et al. [1997] by including more studies on residential water demand as well as by addressing income elasticities of residential water demand.

[5] In contrast to the considerable empirical literature on the effect of prices and income on water demand, the empirical support from the literature for the effectiveness of price instruments to reach multiple goals is rather small. Two interesting examples of social-economic aspects of pricing of water use, however, can be found in the past literature. Darr et al. [1975] and, more recently, Hewitt [1993] have analyzed the responsiveness of low-income groups to changes in prices of residential water demand.

[6] The aim of this paper is to explore the explanatory background factors based on four conditions for an appropriate tariff system for residential water use and to analyze the extent to which these goals are reached in five cities (or urban areas). Using case studies and describing explanatory factors derived from the literature on the economics of water use, section 2 introduces the methodology of this paper, namely, rough set analysis. Rough set analysis is a technique from artificial intelligence and may be interpreted as a tool for meta-analysis of our urban case studies in order to investigate to which extent multiple goals in urban water 
Table 1. Summary Statistics on Drinking Water Facts in The Five Cities Under Consideration (1997)

\begin{tabular}{|c|c|c|c|c|c|}
\hline & Amsterdam & Athens & London & Seville & Tel Aviv \\
\hline Surface area, $\mathrm{km}^{2}$ & 167 & 457 & 1590 & 142 & 50 \\
\hline Surface water, $\%$ & 91.2 & 88.5 & 85 & 100 & 48.5 \\
\hline Groundwater, \% & 7.8 & 11.5 & 15 & 0 & 51.5 \\
\hline Household income, euros/month & 1521 & 900 & 2930 & 1752 & 1760 \\
\hline Unemployment (percentage of the labor force) & 4.4 & 8.6 & 8.1 & 25.3 & 2.6 \\
\hline Liters per head per day (households) & 158 & 110 & 155 & 145 & 137 \\
\hline Population & 718,175 & $3,502,825$ & $7,122,200$ & $1,214,051$ & 349,100 \\
\hline Share of ethnic groups & 43.5 & 5 & 17 & 0.01 & 6 \\
\hline
\end{tabular}

policies are reached. The case studies apply to the water provision of four European cities and one city in the Middle East. (The cities concerned were part of an EU comparative study on water use in metropolitan areas (abbreviated as METRON)). Expert's opinions from the cities are used to examine the extent to which the tariff system has met the policy principles.

[7] Given the small sample of case studies, we use a rough set analysis. Using rough set analysis allows us to use a partly quantitatively and a partly qualitatively oriented data set to assess the importance of critical background factors of successes or failures to reach multiple goals in domestic water policy. The application and results of the rough set analysis are discussed in section 3. Finally, we will finish with some policy conclusions and suggestions for further research in section 4 .

\section{Thematic Issues Related to Four Water Policy Attributes}

\subsection{Research Synthesis and Comparative Information}

[8] The aim of this section is twofold. First, we introduce the necessary empirical ingredients, the case studies and the background factors, derived from the theory of the economics of water use that influence the extent to which principles of an appropriate tariff system are met. Second, with the help of the empirical ingredients we gradually introduce rough set analysis. Rough set analysis is a technique from artificial intelligence and may be interpreted as a tool for meta-analysis. In the past decade, meta-analysis has been developed in the context of the experimental sciences and refers to the statistical analysis of research results of studies performed previously. It should thus be distinguished from primary and secondary analysis [Glass, 1976] referring to an original and an extended investigation of one specific data set, respectively. Meta-analysis is concerned with the analysis of some sort of statistical summary indicator (e.g., a mean, a correlation coefficient, or an elasticity) that has been derived from previously performed (case) studies. As such, it is, in fact, an indirect analysis of various data sets employed in the underlying studies. In the context of metaanalysis a toolbox of statistical techniques has been developed [see, e.g., Hedges and Olkin, 1985; Cooper and Hedges, 1994], and its application is now gaining ground in economics as well (see van den Bergh et al. [1997] and Florax et al. [2001] for recent overviews). Thus metaanalytical methods aim to create a research synthesis out of various underlying data basis. They allow us to undertake a solid comparative analysis of various case studies in relation to water policy in our five case studies.
[9] For the purpose of our comparative study on the importance of background factors of water provision, on urban water tariff systems, and on the achievement of various goals, we are faced with a small sample containing a mixture of qualitative and quantitative data, so that standard techniques (e.g., metaregression, effect-size methods, or logit models) cannot be employed. In our empirical analysis we deploy a recently developed method for qualitative classification techniques on the basis of artificial intelligence, namely, rough set analysis [see van den Bergh et al., 1997; Pawlak, 1991; Slowinski, 1991]. The remainder of this section is as follows. We start with a description of water provision in five urban areas in section 2.2. Second, the four principles of an appropriate tariff system are discussed in section 2.3. Furthermore, we introduce factors that might be used to measure the extent to which the principles of an appropriate tariff system for water use are met. This is carried out with the help of literature on the economics of water use and the case studies. Third, we describe the collection of expert's judgments in section 2.4. Experts from the case cities studied the water provision on water use extensively and are able to judge the extent to which the water tariff system employed in their city met the principles of an appropriate tariff structure. Finally, we introduce, with the help of background factors and expert judgments, the technique of rough set analysis in section 2.5.

\subsection{Introduction to the Case Cities}

[10] The sample of our case cities considered is small, but both local and external experts have studied them intensively. These cities also exhibit considerable differences, making a comparative analysis worthwhile. Table 1 shows some characteristics of the water systems in these places.

[11] Each of the cities considered has, for example, its own type of water scarcity problems. Three of the cities have to deal with the quantitative dimension of scarcity (Athens, Seville, and Tel Aviv), while one city has to deal with the qualitative dimension of scarcity (Amsterdam). Furthermore, there are remarkable differences in governance structures of the water sector. On the one hand, the water sector in the UK is privatized, while on the other hand, in Israel the water sector is under state control. This section concisely presents the water provision in the cities under consideration.

\subsubsection{Amsterdam}

[12] Amsterdam, Netherlands, located in the northwestern part of Europe, captures an area of $167 \mathrm{~km}^{2}$. The population of the Amsterdam municipality consists of 718,175 people. (This is the number of people in the area of the city of Amsterdam. The distribution area of the Amsterdam Water 
Supply Company is somewhat larger and covers the areas of Amsterdam, Diemen, and Muiden (748,894 inhabitants in total). The Amsterdam Water Supply Company (AWSC) carries out water provision in Amsterdam. The AWSC is an administrative part of the municipality of Amsterdam; it is separated from sewage control and wastewater management. The water sources used in Amsterdam are the Rhine River and the Bethune Polder. It is noteworthy that the use of the Rhine River requires a considerable amount of efforts to purify water (about four times the standard purification efforts of a water company that uses ground water sources). The performances of the network are, however, outstanding in comparison with other cities. Water use in Amsterdam is for a substantial part not metered and payments for water use depend on housing characteristics, such as the number of rooms. The losses of the distribution network are estimated at $2.3 \%$ of the total inputs [VEWIN/Anderson Consulting, 1999].

\subsubsection{Athens}

[13] Athens, Greece, is located in the southeastern part of Europe and consists of an area of $457 \mathrm{~km}^{2}$. The number of inhabitants in the metropolitan area is around 3.5 million people. The water company responsible for the water supply in Athens is the EYDAP. Recently, regulatory decisions divided the water company into a public sector company with the ownership of the resources and EYDAP S.A. with the ownership of the network and sewage infrastructure. In the new situation, up to $49 \%$ of the assets can be financed with public capital. The catchment system consists of the Mornos, Evinos River, and the Biotikos aquifer with a total resource availability of $590 \mathrm{hm}^{3}$ per year. The distribution loss is estimated to be $\sim 19 \%$ of the distribution input.

\subsubsection{London}

[14] London, United Kingdom, located in the northwestern part of Europe, consists of an area of $1590 \mathrm{~km}^{2}$. The number of inhabitants in the entire greater London area reaches 7.1 million people. The Thames Water Company carries out a considerable part of the water supply in London. The main source the company uses is water from the Thames River. The Thames Water Company is, like the rest of the water sector in the United Kingdom, privately organized, and its shares are traded at the London Stock Exchange Market. The regulating institutes are responsible for three parameters controlling the prices/standards, environment, and drinking water quality. The distribution losses are $23.7 \%$ of the distribution inputs.

\subsubsection{Seville}

[15] Seville, Spain, is situated in the southwestern part of Europe, and its surface counts for $142 \mathrm{~km}^{2}$. Its number of inhabitants reaches around 1.2 million people. Responsible for the water provision and sewage collection is EMASESA, a municipality-owned company. The available resources are around $117 \mathrm{hm}^{3}$ a year; Seville is completely dependent on surface water. The main source is the Guadalquivir River. The distribution losses of the network count for $\sim 22 \%$ of the total distribution inputs.

\subsubsection{Tel Aviv}

[16] Tel Aviv is the smallest city in our sample; it is located in the Middle East and captures an area of $50 \mathrm{~km}^{2}$. The number of inhabitants of Tel Aviv-Yafo reaches 350 thousand people. MEKOROT, a state-owned company, is responsible for water production and purification for the whole country, while the municipality of Tel Aviv-Yafo is responsible for the distribution. The water commissioner, who operates under the responsibility of the Ministry of Infrastructure, is responsible for all aspects of water management. Resources are equally shared all over the country and between users. The main resource used by the MEKOROT water company is the Sea of Galilee. Tel Aviv shares the water resources with all parts of the country including the southern dry areas of Israel. Around 9.2\% of the distribution inputs count in Tel Aviv for losses.

[17] The five cities offer an interesting spectrum of various management principles and geographical variations in European water supply. Despite the diversity among these European cities, there may also be important commonalities such as the dimensions of scarcity and high distribution losses. These will be further discussed in a thematic way in section 2.3.

\subsection{Theoretical and Empirical Aspects of Water Tariff Principles}

[18] The purpose of this section is to discuss four principles for an optimal tariff system for water use presented in the general literature on the economics of water use and to introduce variables that can be used to measure the extent to which the principles can be met [see Baumann et al., 1998; Dalhuisen et al., 2000a; Hall and Hanemann, 1996; Darr et al., 1975, 1976; Young and Haveman, 1985]. Clearly, background factors of the water provision are important to explain the extent to which the principles presented above are reached, but in practice, these principles may outweigh each other. A clear example is the case where the equity principle is met, resulting in abundant supply and use of water because of its low share in the household's budget, but where then the economic efficiency principle is not met at all. We discuss the conditions of a tariff system in this section in the following order: (1) the full cost recovery principle, (2) the economic efficiency condition, (3) the equity principle, and (4) the administrative feasibility and efficiency criterion.

\subsubsection{Principle 1: Full cost recovery}

[19] The water industry is a capital-intensive sector. Equipment to purify and transport water requires considerable investments. For a continuing fulfillment of water demand a water company should be able to cover at least the production and distribution costs. That means that revenue stability is of utmost importance for new and maintenance investments. However, revenue stability may sometimes not be reached in a number of countries because of external circumstances (e.g., calamities). In case of a public water company the deficit to fill the gap between costs and revenues is usually covered to a large extent by taxpayers [Braadbaart, 2000]. Cost recovery is, however, a multifaceted phenomenon. There are three definitions of cost recovery. Operational cost recovery means that the revenues are at least equal to the operational costs of water provision. When capital costs are included and covered by the revenues of water services, there is a situation of full service cost recovery. In case environmental costs and other external costs of water services are included (such as the costs of environmental damage), a situation of full water cost recovery is reached. 
[20] Full service cost recovery and full water cost recovery are complex issues in water management practice. In case of full service cost recovery, the determination of capital costs depends highly on the chosen depreciation schedule. Full water cost recovery is highly determined by external costs that are difficult to measure. For the assessment of environmental costs the environmental economics literature provides various methods. Each of these valuation methods results in different estimates of nonmarketable costs (such as environmental costs). For an extensive overview of these methods we refer to van den Bergh [1999]. A noteworthy aspect of the full cost recovery principle is the multigenerational dimension. When determining the price of water for residential use, the interest of future generations, which cannot influence the current needs, should be taken into account in order to supply them at least with a fair amount of water of a sufficient quality. This means that prices (as one of the measures) should be set at a level that would ensure that the stock of available water be affected to a minimum extent through excessive use (e.g., overpumping) and excessive pollution.

[21] For the sake of ease of measurement we will use here the full service cost recovery definition [OECD, 1998; Perman et al., 1996; Hanemann, 1998]. The first indicator employed is the profit (or loss) situation of the water company. The water companies of Seville and Athens have often coped with losses in case of drought periods, i.e., periods in which the water availability is low. If the financial costs recovery principle, which is part of the full service cost recovery, is not met for a long period, this may result in lower reliability of the water supply and/or financial problems of the water company [Kallis and Coccossis, 2000; Murillo and Mateos, 2000].

[22] Constant low water availability frequently shows up in case of the water provision of Tel Aviv [Tal, 2000]. In case of low water availability, prices would have to be adapted to the changing circumstances in drought periods; that is, prices will have to increase in order to cover costs to guarantee future water demand. The option, which results for policy makers in case of a publicly owned water company, is subsidizing the water company. This could be done in several ways: first, subsidizing for an amount equal to the losses made (in the case of Seville) or, second, subsidizing part(s) of the network (the case of Tel Aviv). Related water supply subsidies, be they a more indirect form of subsidies, are the structural funding by the European Union. For the purpose of social cohesion or to enhance economic growth of a certain region the European Union may subsidize investments in various sectors (including the water sector). Tariff systems can be adapted to decrease capital costs, and then a situation of full operational and service cost recovery is easily reached. However, the additional environmental effects and costs are difficult to trace, and the subsidies might give the water companies less incentive to invest in their networks [Boymanns, 2001].

[23] A next step that is important to consider is the taxes to cover investment costs or environmental costs. A next important step is the institutional setting, i.e., the governance structure of the water company. Public companies do not have high priorities to generate profits and are driven by other targets than private companies, which should guaran- tee a certain profit for their shareholders [cf. Ruys et al., 2000].

\subsubsection{Principle 2: Economic efficiency}

[24] From the point of view of economic efficiency the rate structure should be such that (1) it provides incentives to the users to use water efficiently (which requires that prices should reflect marginal costs) and (2) it provides optimal incentives to the market to engage in the development of and investment in water saving technologies.

[25] The economic efficiency principle boils down to the condition that prices should equal long-run marginal social costs. Two issues arise here. First, it is the social instead of private marginal costs of supply that matters, thus including the external costs such as the costs of depletion and pollution. Second, the long-run cost is very important, which includes capital and operating costs associated with infrastructure facilities. The use of marginal costs has farreaching consequences and implies, for example, that water during peak hours or during summer months should be relatively more expensive because of higher supply costs.

[26] One interesting study concerning underlying factors, such as the water price, influencing the adaptation of water saving devices is the study of Renwick [1996]. In the study the author estimates a simultaneous equation model, with the help of data derived from a survey on water use in Goleta and Santa Barbara (in the western part of the United States). One of the statistical methods deployed is a logit model that tries to derive the factors explaining the adaptation process of water-saving devices such as retrofitting, for the purpose of water saving. In the analysis, however, we do not find rate design variables (such as adapting block rates, where a first amount of water consumed is differently priced from the subsequent amount of water consumed) as one of the explanatory variables to adapt water saving devices.

[27] An important feature of tariff systems in case of economic efficiency is the tariff structure (e.g., a fixed fee or an increasing block rate schedule for water use; see below) and the price of each unit of water consumed. The tariff structure of water is, in principle, comparable to that of any other public utility, such as gas, electricity, telecommunications, and the like. Tariff systems can generally be subdivided into three main categories: (1) the price per unit of water is constant; (2) the price of water is constant within discrete intervals of water use but increasing between different intervals (an "increasing block rate tariff"); (3) as category 2 but with decreasing prices between intervals (a "decreasing block rate structure"). The existence of different rate structures influences efficient water use. Decreasing block rate structures do, in general, not contribute to efficient water use because expanding the consumption will, in general, result in a lower price per unit for water use. A related issue, which is a serious drawback to reach cost recovery and economic efficiency, is the presence of subsidies for individual users. Subsidies will usually result in changes in the incentive structures.

[28] We expect a decrease in the achievement of economic efficiency when subsidies are present [de Moor, 2000]. A complementary issue is the linkage between water payment and water usage: when there is no link between water use and water payments, the tariff system is expected to have a low score on the economic efficiency principle. The next indicator taken into account in our analysis is the 
water use level. If the water use levels per capita are high, there is room for saving water. If water levels per capita are low, the maneuver space for saving water is much lower, probably because then the actual water use is closely related to the subsistence requirement [Baumann et al., 1998].

\subsubsection{Principle 3: Equity}

[29] Water is of vital importance for every human being. Each person should be able to acquire at least a sufficient amount of water in order to live in healthy conditions and to participate in societal life. A related element often referred to in the theory on water use is the fact that household payments for water should not be a disproportional share of the household budget.

[30] When the social aspects of water use are considered as important, this principle might result in policy measures such as subsidizing, in particular, low-income households. Hewitt [1993] discusses, with the help of a data set on residential water use in Denton, Texas, effects of price changes of residential water demand for different income groups. In the analysis, Hewitt found that high-income groups turn out to be more responsive to changes in prices, which means that they are able to bring their water use down with a relatively high percentage. A possible reason for this might be the relatively low water use of low-income groups that might be close to the basic subsistence principle of water.

[31] To measure the extent to which the equity principle is met, we employ here two indicators. The first indicator is the level of the disposable income in the cities under consideration. Low-income groups consume an amount of water closer to the subsistence level than high-income groups. A balanced income structure in terms of a fair share of low-income groups contributes to the fulfillment of the equity principle. The second indicator is related to the first indicator and is the level of unemployment which might lead to social support by the government that is necessary to care at least for the subsistence principles, with probably measures to lower their water bill.

\subsubsection{Principle 4: Administrative feasibility and efficiency}

[32] The abovementioned principles often need very complex rate structures and a complex ramification of administrative efforts. Administrative efficiency and feasibility is the extent to which the cost recovery principle, the equity principle, and the economic efficiency condition of the employed tariff structure are reached at minimum costs. There are, however, also practical constraints deriving from administrative feasibility and efficiency of the tariff system for water use. First, for example, to make efficiency possible, water use should be administered and monitored. In order to achieve this, meters have to be installed, and these should be read regularly.

[33] Furthermore, reaching marginal pricing requires knowledge about the external (often nonmeasurable) costs, whereas complex measuring systems may not be practicable. Then, we obviously face a tradeoff between the level of transparency and the fulfillment of principles needed for the tariff system.

[34] To a large extent, the administrative feasibility is dependent on the metering percentage and the tariff structure in the city under consideration. When payments for water use are fixed, we expect lower administrative efforts and hence a higher contribution to the achievement of administrative efficiency of a tariff system because no administrative efforts are needed for reading water meters.

[35] The next indicator is population growth. High population growth may result in an extra demand for connections to the pipeline infrastructure that results in additional administrative efforts. A high percentage of ethnic minorities will increase administrative efforts, when they need more information in their own language or specific information about their water use. (For leaflets in a foreign language this is probably a one time administrative effort. However, regularly repeating water-saving campaigns and other information regarding water use are likely only effective when it is also done in the language of the urban minorities.) A case study on water use in Amsterdam shows remarkable differences in water consumption between ethnic and nonethnic inhabitants of Amsterdam [NIPO, 1997].

[36] The last indicator is the number of connections per kilometer of the network. A high number of connections per kilometer network results in a higher probability of increasing administrative feasibility because it is possible to read more meters within the same time.

\subsection{Strategic Information on Urban Water Issues}

[37] To carry out an empirical analysis, we have developed a questionnaire in which we asked a group of qualified experts in each city to which extent the four principles of an optimal tariff system for water use were met in their city. Because of the resulting limited and qualitative data set, rough set analysis is then a suitable way of analyzing the background factors responsible for the extent to which the fulfillment of the four principles of a water tariff system differ in each city.

[38] The experts queried were highly involved in the water management practices in the city considered. These experts, mostly academic researchers who had done an extensive research on the water provision in their city, judged carefully the extent to which the principles of a tariff structure were fulfilled in the cities considered. The questionnaire (available at http://www.tinbergen.nl/ dalhuisen/Questionnaire. $\mathrm{htm}$ ) consisted of a number of statements to be commented upon by the experts. One of the statements to be judged, for instance, was the following: the total water payments of the households received by the water company is at a level that enables the water company to cover water costs. When the expert totally agreed with the statement, a score of 1 was included in the data matrix. When the expert totally disagreed with the statement, we included a score 7 in the data matrix. To ensure sufficient variation in the data table, five intermediate classes were added between the two extreme values. Table 2 shows the scores an expert might give to the extent to which a certain principle of the tariff system for water use is met in the city considered, based on a sevenpoint scale.

[39] When more than one expert was consulted, this was also included in our database. In this case, the different angles increase our knowledge on the various tariff systems employed. The scores given for the extent to which the four principles of an optimal tariff system are met were investigated in our application with the help of rough set analysis. 
Table 2. Judgment Options Available for the Experts

Value of the Attributes

\begin{tabular}{ll}
\hline++ & the principle is totally matched with the tariff structure employed for water use \\
++ & the principle is almost met \\
+ & the principle is met to a large degree \\
0 & the principle is not clearly met nor unmet \\
- & the principle is to a large degree not met \\
-- & the principle is almost unmet \\
--- & the principle is not matched at all with the employed tariff structure for water use \\
\hline
\end{tabular}

[40] As mentioned above, rough set analysis is a classification technique that is able to handle incomplete and imprecise (e.g., soft or categorical information) nonstochastic data on the basis of qualitative attributes. The attributes (coded in Table 3) act as explanatory variables, and the expert opinions on attributes as "dependent" variables [Nijkamp et al., 2000].

\subsection{Rough Set Analysis: An Introduction}

[41] Rough set is a recently developed nonparametric statistical method. For an extensive theoretical description we refer to Pawlak [1991] and Slowinski [1991]. Examples of applications of rough set analysis to environmental economic issues are given by van den Bergh et al. [1997], Nijkamp [2000], and Masurel et al. [2001]. These applications relate, among other things, to pesticide use in agriculture, urban land use policy, and transportation policy.

[42] A set for which it is uncertain to classify a group of certain objects unambiguously can be characterized as a rough set. In our water management application, we focus on the distinct experts' judgments concerning the extent to which the four principles of an optimal water tariff are met.

[43] The classification of categorical information is then dependent on the degree of "granularity." In the theory of rough sets we assume the existence of a certain finite set of objects to be classified. The extent to which, in our study, the four principles are fulfilled requires a classification of items characterizing these principles in various dimensions. In section 2.3 we describe relevant background factors that are often mentioned in the literature on the economics of water use and that will likely have an impact on the extent to which the optimal tariff structure is reached. The information is gathered in terms of attrition of relevant attributes of the water management systems to distinct classes (e.g., the diversified governance structures or the existence of various kinds of subsidies) or factual knowledge (e.g., leakage percentage or urban unemployment rate). An attribute and a coded value of this attribute can express each of these properties. Table 4 shows the information of each of the attributes. Since the classification is not straightforward, we have a case of rough sets. The opinions of the experts can now formally be described as a set $\{Y\}$ :

$$
Y=\left\{X_{i j}^{n}\right\}
$$

where $n$ is the principle under consideration (e.g., the cost recovery principle), $i$ is the expert concerned, and $j$ is the city considered. In Table 4 we may represent the set of attributes. In the case of, for example, cost recovery, we might have a set $R$ consisting of attributes. So $R=\{c 1, c 2$, $c 3, c 4, c 5, c 6\}$. For each attribute we have the relevant sets with corresponding scores or codes of these attributes. For example, for the first attribute we may have a set $V$ of values of these attributes. For the first attribute the characteristic set may be $V_{c 1}=\{1,2\}$, where $c_{1}$ refers to the attribute "performance of the water company," which can be represented by two values: "losses in the period of drought" (code 1) or "water company survives with subsidies" (code 2). Table 4 shows that the value for Amsterdam, London, and Tel Aviv equals 2, and for Athens and Seville, the value equals 1 .

[44] The attributes may be used to define equivalence relationships or mappings. For example, the experts' judgment on the extent to which cost recovery is met can be described as follows: $Y_{\text {cost recovery }} \rightarrow P\left(V_{c_{1}}, \ldots, V_{c_{6}}\right)$. This can be interpreted as follows: the reason that cost recovery is almost met according to one of the expert's judgments might be, for example, the performance of the water company (a value 2 in Table 4) and the presence of government subsidies for cost coverage of (parts of) the network (value 2). These relationships can be used to distinguish equivalence classes. Objects belonging to the same equivalence classes, based on the features concerned, are indiscernible. In case of multiple attributes the intersection of the attributes results in equivalence relationships that results in a more precise classification than in case of a single equivalence relationship. The reduct is then a subset of all attributes. Adding other attributes to the reduct does not result in a more precise classification, and deleting an attribute of the reduct will result in a less precise classification of the objects under consideration. Sometimes we find an attribute belonging to the core of a set. The core is the class of all indiscernible equivalence relationships. The combination of attributes and experts' opinions can be regarded as a decision table.

[45] Next, on the basis of the information table with conditions (variables such as in our case the characteristics of the cities) and the decision (or response) attributes we are able to construct decision rules (of an "if. ..then" nature), which represent an implicit relationship between the background variables and the scores on the number of policy principles given by experts in various case cities. The strength of the indicator might be explained with the help of the frequency of the indicator or attribute in each decision rule. If certain attributes occur frequently in the same decision rules, they have a considerable impact on the performance 
Table 3. Description of the Attributes and Their Classes

\begin{tabular}{|c|c|}
\hline Attributed Values & Classes \\
\hline \multirow{2}{*}{\multicolumn{2}{|c|}{$\begin{array}{l}\text { Cost Recovery Principle } \\
\qquad \begin{array}{l}\text { 1: losses in periods of droughts } \\
\text { 2: water company is in general profitable or the water company survives } \\
\text { with subsidies }\end{array}\end{array}$}} \\
\hline & \\
\hline \multirow[t]{4}{*}{$\mathrm{c} 2$, subsidies for construction purposes ${ }^{\mathrm{a}}$} & 1: EU structural funds for cost coverage of (parts of) the network \\
\hline & 2: government subsidies for cost coverage of (parts of) the network \\
\hline & 3 : combination of 1 and 2 \\
\hline & 4: no subsidies \\
\hline \multirow[t]{3}{*}{ c3: taxes on water use ${ }^{a}$} & $\begin{array}{l}\text { 1: environmental taxes for the purpose of coverage of external costs (e.g., } \\
\text { environmental costs) }\end{array}$ \\
\hline & 2: construction taxes; taxes to finance construction fees \\
\hline & 3: other taxes \\
\hline \multirow[t]{2}{*}{$\mathrm{c} 4$, institutional:company structure ${ }^{\mathrm{a}}$} & 1: private water company \\
\hline & $\begin{array}{l}\text { 3: combination, i.e., parts of the water provision is public (e.g., the } \\
\text { network) and parts of the network are private }\end{array}$ \\
\hline$c 5$, distribution losses ${ }^{a}$ & $\begin{array}{l}\text { leakage percentage of the distribution inputs through poor network } \\
\text { conditions }\end{array}$ \\
\hline c6: Percentage surface water ${ }^{\mathrm{a}}$ & percentage of the sources which can be classified as surface water \\
\hline
\end{tabular}

ec1, tariff structure for households ${ }^{\mathrm{a}}$

Economic Efficiency Principle

1: a unit water payment system; water payments are calculated on the basis of number of rooms, presence of a garden, etc.

2: fixed system; payments are independent of water use (payments are, for example, a percentage of the rent)

3: a constant price per unit of water use

4: an increasing block rate schedule; the first amount of water is priced with a lower tariff than the subsequent amount of water

5: a decreasing block rate schedule; the first amount of water is priced with a higher tariff than the subsequent amount of water

ec2, subsidies for individual users ${ }^{\mathrm{a}}$

ec3, connection between payment and water use $\mathrm{a}^{\mathrm{a}}$

ec4, residential water use

e1, Household income in the city

e2, Unemployment

a1, metering percentage

a2, population growth

a3, percentage of ethnic groups

$\mathrm{a} 4$, connection $/ \mathrm{km}$ network ${ }^{\mathrm{a}}$
1: individual consumers may be subsidized

2: no subsidies for individual users available

1: water payments depend on water use

2: no direct connection between water payments and water use residential water use (liters per head per day)

Equity Principle

disposable income (in euros)

unemployment rate (percentage of the labor force which is unemployed)
Administrative Efficiency and Feasibility Principle

percentage of households whose water use is metered:

1: $0 \leq$ metering percentage $\leq 0.25$

2: $0.25<$ metering percentage $\leq 0.50$

3: $0.50<$ metering percentage $\leq 1.00$

population growth in the city per annum (percentage)

percentage of ethnic groups:

1: $0 \leq$ percentage ethnic minorities $\leq 0.10$

2: $0.10 \leq$ percentage ethnic minorities $\leq 0.20$

3: percentage ethnic minorities $\geq 0.20$

connections per kilometer of the network, calculated as total number of connections/total length of nework $(\mathrm{km})$

\footnotetext{
${ }^{\mathrm{a}}$ Manageable factors
}

indicator characterizing the case study and can hence be considered as a critical factor. We will first present the principles for the codified information table, as shown in Table 4

[46] The rough set analysis is carried out with the help of the computer program Rough Set Data Explorer (ROSE, see http://www-idss.cs.put.poznan.pl/rose/). The algorithm of this program constructs the best possible decision rules to explain the scores given by experts and is able to handle different expert opinions. The decision rules are of an if...then nature and are constructed on the basis of the attributes given in Table 4. External variables that could be influenced by the water company are noted in Table 4. The results of the rough set analysis are presented in Section 3. For further details on rough set analysis and the software used we refer to 
Table 4. Empirical Values of Attributes of the Principles for Tariff Systems Employed in the Case Studies Under Consideration

\begin{tabular}{|c|c|c|c|c|c|c|c|c|}
\hline Attributes & $\begin{array}{l}\text { Expert } 1 \text { on } \\
\text { Amsterdam }\end{array}$ & $\begin{array}{l}\text { Expert } 2 \text { on } \\
\text { Amsterdam }\end{array}$ & $\begin{array}{c}\text { Expert } 3 \text { on } \\
\text { Athens }\end{array}$ & $\begin{array}{l}\text { Expert } 4 \text { on } \\
\text { London }\end{array}$ & $\begin{array}{c}\text { Expert } 5 \text { on } \\
\text { Seville }\end{array}$ & $\begin{array}{l}\text { Expert } 6 \text { on } \\
\text { Seville }\end{array}$ & $\begin{array}{l}\text { Expert } 7 \text { on } \\
\text { Seville }\end{array}$ & $\begin{array}{c}\text { Expert } 8 \text { on } \\
\text { Tel Aviv }\end{array}$ \\
\hline \multicolumn{9}{|c|}{ Cost Recovery Principle } \\
\hline Performance of the water company (c1) & 2 & 2 & 1 & 2 & 1 & 1 & 1 & 2 \\
\hline Subsidies for construction purposes (c2) & 2 & 2 & 1 & 4 & 1 & 1 & 1 & 2 \\
\hline Taxes on water use (c3) & 1 & 1 & 3 & 3 & 3 & 3 & 3 & 3 \\
\hline Institutional:company structure (c4) & 2 & 2 & 3 & 1 & 2 & 2 & 2 & 2 \\
\hline Distribution losses (c5) & 2.3 & 2.3 & 19.1 & 23.7 & 22 & 22 & 22 & 9.2 \\
\hline Percentage surface water (c6) & 91.2 & 91.2 & 88.5 & 85 & 100 & 100 & 100 & 48.5 \\
\hline Score given by expert & 3 & 3 & 5 & 1 & 2 & 3 & 5 & 1 \\
\hline \multicolumn{9}{|c|}{ Economic Efficiency Principle } \\
\hline Tariff structure for households (ec1) & 1 & 1 & 3 & 3 & 3 & 3 & 3 & 4 \\
\hline Subsidies for individual users (ec2) & 1 & 1 & 2 & 1 & 2 & 2 & 2 & 2 \\
\hline Connection between payment and water use (ec3) & 2 & 2 & 1 & 2 & 1 & 1 & 1 & 1 \\
\hline Residential water use (ec4) & 158 & 158 & 110 & 155 & 145 & 145 & 145 & 137 \\
\hline Score given by expert & 7 & 7 & 6 & 1 & 6 & 7 & 5 & 7 \\
\hline \multicolumn{9}{|c|}{ Equity Principle } \\
\hline Household Income in the city (e1) & 1521 & 1521 & 900 & 2930 & 1752 & 1752 & 1752 & 1760 \\
\hline Unemployment (e2) & 4.4 & 4.4 & 8.6 & 8.1 & 25.3 & 25.3 & 25.3 & 2.6 \\
\hline Score given by expert & 1 & 1 & 6 & 3 & 1 & 2 & 3 & 1 \\
\hline \multicolumn{9}{|c|}{ Administrative Efficiency and Feasibility Principle } \\
\hline Metering percentage (a1) & 0 & 0 & 100 & 17 & 47 & 47 & 47 & 100 \\
\hline Population growth (a2) & 0.5 & 0.51 & 0.46 & 0.32 & 0.98 & 0.98 & 0.98 & -0.2 \\
\hline Percentage of ethnic minorities (a3) & 43.5 & 43.5 & 5 & 17 & 0.01 & 0.01 & 0.01 & 6 \\
\hline Connection $/ \mathrm{km}$ network (a4) & 187.98 & 187.98 & 232.45 & 105.48 & 85.13 & 85.13 & 85.13 & 121.41 \\
\hline Score given by expert & 6 & 5 & 4 & 1 & 1 & 4 & 3 & 6 \\
\hline
\end{tabular}

Sources: Case studies Amsterdam, Athens, London, Seville and Tel Aviv.

van den Bergh et al. [1997], Pawlak [1991], and Slowinski [1991].

\section{Application, Results, and Interpretation}

[47] An optimal tariff system for residential water use would ideally have to meet all principles discussed in section 2.3. Now the question is to which extent these desiderata are fulfilled in urban water practice. We use the information from the in-depth case studies on water management practices in the five metropolitan areas under consideration for the empirical analysis of the underlying factors that are responsible for the extent to which the principles are met [Castro et al., 2000; Dalhuisen et al., 2000b; Kallis and Coccossis, 2000; Murillo and Mateos, 2000; Tal, 2000]. Because of the limited data set the mixture of quantitative and qualitative data and the need for a flexible model design make the use of the rough set method suitable for our purposes. Table 4 presents the empirical information on the attributes of the principles on the basis of the structure of classes presented in Table 3 as well as the opinions of the experts. The attribute "leakage percentage of the distribution system" (C5) is, in Seville, for example, $22 \%$. The full water cost recovery principle is according to the judgment of one of the local experts (expert 7) to a large degree not met (i.e., a score of 5). The rough set analysis is now applied to each of the four main categories in Tables 3 and 4 separately.

[48] The decision rules are given in Table 5, and the minimal sets are given in Table 6. A minimal set is a set of attributes that cannot be eliminated. Elimination of attributes makes classification of the scores given by experts and construction of decision rules impossible. Table 5 shows the decision rules for the principles discussed above. Approximation rules are like decision rules, but because of differences in opinions, they are an approximation of the attributes and the degree to which extent the discussed principles of a tariff system are met. When the water company is, in general, profitable and when there are various taxes included in the water tariff system, this system meets entirely the full service cost recovery principle. The score is, in this case, equal to 1 . The percentage of surface water does not give a clearer picture. Owing to different opinions and low data availability on other important factors responsible for full service cost recovery, such as capital, there is no clear indication for the impact of purification efforts on full service water cost recovery. In general, the equity principle is well met (scores 1, 2, and 3). Higher disposable incomes might result in a score further away from total agreement of the local experts (e.g., in London the equity principle is met to a large degree).

[49] The system of water payments which are independent of water use does not clearly result in more incentives or investments in water saving devices. The same story can be told for the increasing block rate tariff system such as in Tel Aviv. The absence of information on the location of the switch point, the point where the prices per unit for water use switch, might be problematic. High water use per capita might indicate that there is room to save water, but the incentives are not provided by the tariff system. A score of 6 in the second decision rule might indicate an absence of purchasing power to buy water-saving devices. 
Table 5. Decision Rules for the Four Principles

\begin{tabular}{|c|c|}
\hline Principle & Rules \\
\hline Full service cost recovery & $\begin{array}{l}\text { rule } 1:(\mathrm{c} 1=2) \text { and }(\mathrm{c} 3=3) \Rightarrow(\mathrm{d} 2=1) \\
\text { rule } 2:(\mathrm{c} 6=91.2)=>(\mathrm{d} 2=3) \\
\text { rule } 3:(\mathrm{c} 6=88.5)=>(\mathrm{d} 2=5) \\
\text { number of approximate rules } \\
\text { rule } 4:(\mathrm{c} 6=100) \Rightarrow(\mathrm{d} 2=2) \text { or }(\mathrm{d} 2=3) \text { or }(\mathrm{d} 2=5)\end{array}$ \\
\hline Equity & $\begin{array}{l}\text { rule } 1:(\mathrm{e} 1=1521)=>(\mathrm{d} 1=1) \\
\text { rule } 2:(\mathrm{e} 1=1760)=>(\mathrm{d} 1=1) \\
\text { rule } 3:(\mathrm{e} 1=900) \Rightarrow>(\mathrm{d} 1=2) \\
\text { rule } 4:(\mathrm{e} 1=2930)=>(\mathrm{d} 1=3) \\
\# \text { Approximate rules } \\
\text { rule } 5:(\mathrm{e} 1=1752)=>(\mathrm{d} 1=1) \text { or }(\mathrm{d} 1=2) \text { or }(\mathrm{d} 1=3)\end{array}$ \\
\hline Economic efficiency & $\begin{array}{l}\text { rule } 1:(\mathrm{ec} 4=155) \Rightarrow(\mathrm{d} 1=1) \\
\text { rule } 2:(\mathrm{ec} 4=110) \Rightarrow(\mathrm{d} 1=6) \\
\text { rule } 3:(\mathrm{ec} 1=1)=>(\mathrm{d} 1=7) \\
\text { rule } 4:(\mathrm{ec} 1=4) \Rightarrow>(\mathrm{d} 1=7) \\
\text { number of approximate rules } \\
\text { rule } 5:(\mathrm{ec} 4=145) \Rightarrow>(\mathrm{d} 1=5) \text { or }(\mathrm{d} 1=6) \text { or }(\mathrm{d} 1=7)\end{array}$ \\
\hline Administrative efficiency feasibility & $\begin{array}{l}\text { rule } 1:(\mathrm{a} 1=17) \Rightarrow(\mathrm{d} 1=4) \\
\text { rule } 2:(\mathrm{a} 2=0.46)=>(\mathrm{d} 1=4) \\
\text { rule } 3:(\mathrm{a} 2=-0.2) \Rightarrow(\mathrm{d} 1=5) \\
\text { number of approximate rules } \\
\text { rule } 4:(\mathrm{a} 1=0) \Rightarrow(\mathrm{d} 1=5) \text { or }(\mathrm{d} 1=6) \\
\text { rule } 5:(\mathrm{a} 1=47) \Rightarrow>(\mathrm{d} 1=1) \text { or }(\mathrm{d} 1=5)\end{array}$ \\
\hline
\end{tabular}

[50] A negative population growth results in lower efforts to administer water use, and therefore the tariff system can easily meet the administrative and feasibility principle. Low metering percentage does not result in substantial efforts to administer water use.

[51] Looking at the decision rules, it is easy to observe tradeoffs between the four policy principles. When water companies choose a decreasing block rate schedule or a unit system such as the one deployed in Amsterdam, experts judge the economic efficiency as very low. Both structures provide almost no economic incentives for water saving by higher prices for excessive water use and will not influence the people's household budget, which will, in general, be judged by experts as totally meeting the equity principle.

[52] The minimal sets in Table 6 comprise thus various combined attributes that are needed to explain the extent to which the various principles are met. This is explained for each of the four principles considered. Therefore it is important to know which attributes have a high frequency as these attributes stand out in a more pronounced way in the interpretation of the success rate of achieving an optimal water tariff system.

[53] As to the next step, Table 7 shows the frequencies of the attributes in the minimal sets on the basis of the classes that are reported in Table 3. The decision rules show for a substantial part a pattern according to the lines sketched in the theory and section 2 . We can now observe a clear pattern that water companies are sensitive to events of lower water availability. Continuing low water availability needs continuing subsidization to reach full cost recovery (Tel Aviv). Events of drought will result in losses of the water company when there is no temporary increase in the water price. In this case, full cost recovery is not met. The performance of the water company (the attribute abbreviated as c1) appears in all of the minimal sets.

[54] Another important attribute that is central in the debate on changes in the incentive structure to improve the quality of the environment is the existence of various kinds of subsidies [see OECD, 1997; de Moor, 2000]. Looking at the equity principle, high disposable income (the attribute abbreviated as e1) might be an incentive to design a tariff system in such a way that the equity principle is not met. The unemployment rate and the disposable income of a household in a city are equally important attributes.

[55] The individual water use (the attribute abbreviated as ec4) is an important attribute to explain the scores given by experts concerning the economic efficiency principle. The

Table 6. Minimal Sets

\begin{tabular}{ll}
\hline \multicolumn{1}{c}{ Principle } & \multicolumn{1}{c}{ Minimal Set } \\
\hline Full Cost Recovery & $\{\mathrm{c} 1, \mathrm{c} 6\}\{\mathrm{c} 1, \mathrm{c} 2, \mathrm{c} 3\}\{\mathrm{c} 1, \mathrm{c} 5\}\{\mathrm{c} 1, \mathrm{c} 2, \mathrm{c} 4\}$ \\
Economic Efficiency Principle & $\{\mathrm{ec} 4\}$ \\
Equity Principle & $\{\mathrm{e} 1, \mathrm{e} 2\}$ \\
Administrative Feasibility Principle & $\{\mathrm{a} 2, \mathrm{a} 3, \mathrm{a} 4\}$ \\
\hline
\end{tabular}

\footnotetext{
${ }^{\mathrm{a}}$ See Table 4 for the abbreviations of the attributes.
} 
Table 7. Frequencies of Factors in the Minimal Sets

\begin{tabular}{lc}
\multicolumn{1}{c}{ Attributes } & $\begin{array}{c}\text { Appearance in the Decision } \\
\text { Rules (Percentage) }\end{array}$ \\
\hline Cost recovery principle & \\
c1 & $4(100 \%)$ \\
c2 & $2(50 \%)$ \\
c3 & $1(25 \%)$ \\
c4 & $1(25 \%)$ \\
c5 & $1(25 \%)$ \\
c6 & $1(25 \%)$ \\
Equity principle & \\
e1 & \\
e2 & $1(50 \%)$ \\
Economic efficiency principle & $1(50 \%)$ \\
ec4 & \\
Administrative efficiency and feasibility principle & $1(100 \%)$ \\
a2 & \\
a3 & \\
a4 & $1(33.33 \%)$ \\
\hline
\end{tabular}

level of the per capita water use may be explained from the fact that higher water use provides room for water saving and may result in a low score for economic efficiency. Low water use per capita hardly provides room to save water and results in a high score for economic efficiency.

[56] Low metering percentages, i.e., there are fewer meters to read, result in fewer efforts to administer water use. Therefore the tariff system employed do not need considerable efforts to register water use. The administrative feasibility and efficiency principle is easier to meet. Concerning administrative feasibility and efficiency, three out of four proposed attributes appear to show up in the minimal sets. The population growth in the city, the number of connections, and the number of connections per kilometer network are equally important to explain the scores and deal with additional extra efforts which have to be made to keep up with the extra demand for information and connections.

\section{Conclusions}

[57] This paper has explored the importance of relevant background factors of four principles explaining the extent to which tariffs for residential water use in five case cities (Amsterdam, Athens, London, Seville, and Tel Aviv) meet the principles for an optimal tariff system for residential water use. These principles have been developed in the literature on the economics of water use and deal with the following [Baumann et al., 1998; Dalhuisen et al., 2000a]: (1) the extent to which revenues of a water demand system are equal to the costs of the water production (full water cost recovery principle), (2) the possibility for people to acquire at least a basic amount of water to survive (in other words, payments for water should not be an exceptional share of the budget of a household (equity principle)), (3) the way a tariff system provides proper incentives to save water and to invest in water saving devices (economic efficiency principle), (4) the possibility of and efficiency in administering water use (administrative feasibility and efficiency). For this purpose we have developed a questionnaire for experts involved in studying water management practices in the case cities. Expert scores on the extent to which principles are met were next deployed in a rough set analysis.

[58] An investigation of the minimum set to explain the scores of the tariff system teaches us that an observed pattern in our data set is the difficulty to reach full cost recovery in the cities dealing with regularly low water availability. Low water availability often occurs in periods of drought. Then energy costs are rising because water is obtained from locations farther away from the cities and has to be transported over a larger distance [see Kallis and Coccossis, 2000; Murillo and Mateos, 2000]. The second largest attribute worth mentioning here is the existence of subsidies. Subsidies are, in our case, conceived of as "EU structural funds," "governmental subsidies," and "a combination of both classes." Structural funds are EU subsidies provided for the purpose of, for example, social cohesion or regional development or other development opportunities for a certain region. The outcomes support the views brought forward by earlier research on the role of subsidies in providing incentives with environmentally unfriendly consequences [see, e.g., OECD, 1997, 1998; de Moor, 2000]. This prompts the need for further research on the effects of structural funds. In the cases of Athens and Seville, subsidies for the construction of the water transportation network are usually provided. These cities show a negative score on the full water cost recovery principle. Because of the lack of information (amount of subsidies and/or the mixtures with all kind of other governmental subsidies) we only have limited knowledge of the impact of the existence of subsidies. Additional information on amounts of EU structural funding and governmental subsidies is necessary.

[59] Concerning the equity principle, an interesting pattern observed in the cases employed in our analysis is provided by the high frequencies of low incomes. Policy makers will often tend to design tariffs for water use in such a way that they provide at least a basic amount of water for each citizen. Another observed pattern is the case that a high unemployment percentage results in a high frequency of low incomes (assuming that governments support an unem- 
ployed inhabitant with a minimum income), and in this case, the tariff design will be such that it provides the poor with a basic amount of water as well.

[60] The per capita water use might be responsible for the possibility to save water and is connected therefore to the score of an expert on the economic efficiency principle. Low initial levels of per capita water demand result in little room to save water.

[61] Efficient use of water often requires an extra number of administrative efforts to record and implement. Additional information about water use in the language of different ethnic minorities and the extra demand for connections determined by the population growth and the number of connections per kilometer of the network require administrative efforts and are responsible for explaining the scores on the administrative efficiency and feasibility principle.

[62] An optimal tariff structure might be difficult to reach in case of multiple policy objectives, although a number of factors explained in this paper should be considered as critical in the design of a tariff system. Some of the principles may counteract the other principles; for example, an efficient tariff system for water use may result in an impossibility of certain groups to acquire at least a basic amount of water. Clearly, the attainment of an optimal tariff system for water use may be complex, but the design of effective and efficient tariff systems should be based on clear political economic goals.

[63] Acknowledgments. The authors thank Laura Spierdijk, Giorgos Kallis, Martijn van der Heide, Henri de Groot, and two anonymous referees for stimulating comments on earlier versions of this paper.

\section{References}

Baumann, D. D., J. J. Boland, and W. M. Hanemann, Urban Water Demand Management and Planning, McGraw-Hill, New York, 1998.

Boymanns, D., European Policies and Sustainable Use of Water in Metropolitan Areas. Seville: Institute for Prospective Technological Studies. 2001 .

Braadbaart, O., Piped Water services in developing countries: Why we know so little about utility performance determinants and where to go from here, paper presented at the UNESCO-WOTRO International Working Conference Water for Society, Inst. for Infrastructure, Hydraul. and Environ. Eng., Delft, Netherlands, 8-10 Nov. 2000.

Castro, J. E., E. Swyngedouw, andM. Kaika, Case study "Sustainable Water Use in London," Sch. of Geogr. and the Environ., Univ. of Oxford, Oxford, UK, 2000.

Cooper, H., and L. V. Hedges (Eds.), The Handbook of Research Synthesis, Sage, New York, 1994.

Dalhuisen, J. M., H. L. F. de Groot, and P. Nijkamp, The economics of water: A survey of issues, Int. J. Dev. Plann. Lit., 15, 3-20, 2000a.

Dalhuisen, J. M., C. A. Rodenburg, H. L. F. de Groot, and P. Nijkamp, Case study "Sustainable Water Use in Amsterdam," Econ. and Soc. Inst., Vrije Univ., Amsterdam, 2000b.

Dalhuisen, J. M., R. J. G. M. Florax, H. L. F. de Groot, and P. Nijkamp, Price and income elasticities of residential water demand: Why empirical estimates differ, Tinbergen discussion paper, Tinbergen Institute, Amsterdam, 2001.

Darr, P., S. L. Feldman, and C. S. Kamen, Socio-economic factors affecting domestic water demand in Israel, Water Resour. Res., 11(6), 805-809, 1975 .

Darr, P., S. L. Feldman, and C. S. Kamen, The Demand for Urban Water, Stud. Appl. Regional Sci., vol. 6, Nijhoff, Leiden, Netherlands, 1976

de Moor, A. P. G., Perverse incentives: Subsidies and sustainable development, Inst. for Res. on Public Expenditure, the Hague, Netherlands, 2000. (Available at http://www.ecouncil.ac.cr/rio/focus/report/english/ demoor.htm) de Haas, H., H. El Ghanjou, and L. de Haan, Notes on interdisciplinary research on water management: Obstacles and potentials, lessons from the IMAROM project, paper presented at the UNESCO-WOTRO International Working Conference Water for Society, Infrastructure, Hydraul. and Environ. Eng., Delft, 8-10 Nov. 2000.

Espey, M., J. Espey, and W. D. Shaw, Price elasticity of residential demand for water: A meta-analysis, Water Resour. Res., 33(6), 1369-1374, 1997.

Florax, R. J. G. M. P. Nijkamp, and K. Willis (Eds.), Comparative Envir onmental Economic Assessment, Edward Elgar, Cheltenham, UK, 2001.

Glass, G. V., Primary, secondary, and meta-analysis of research, Educ. Res., $5,3-8,1976$.

Hall, D. C., and W. M. Hanemann, Urban water rate design based on marginal cost, in Marginal Cost Rate Design and Wholesale Water Markets, vol. 1, edited by D. C. Hall, pp. 95-122, JAI, Greenwich, Conn., 1996.

Hanemann, W. M., Determinants of urban water use, in Urban Water Demand Management and Planning, edited by D. D. Baumann, J. J. Boland and W. M. Hanemann, pp. 31-75, McGraw-Hill, New York, 1998.

Hedges, L. V., and I. Olkin, Statistical Methods for Meta-Analysis, Academic, San Diego, Calif., 1985.

Hewitt, J. A., Watering households: The Two-error discrete-continuous choice model of residential water demand, Ph.D. thesis, Univ. of Calif., Berkeley, 1993.

Kallis, G., and H. Coccossis, Case study "Sustainable Water Use in Athens," Environ. and Plann. Lab., Univ. of the Aegean, Athens, 2000.

Masurel, E., P. Nijkamp, M. Tastan, and G. Vindigni, Motivations and performance conditions for ethnic entrepreneurship, Tinbergen discussion paper, Tinbergen Inst., Amsterdam, 2001.

Murillo, E. M., and J. A. Mateos, Case study "Sustainable Water Use in Seville," Empresa Municipal de Abastecimiento Y Saneamiento de Aguas de Sevilla, S.A., Seville, Spain, 2000.

Nijkamp, P., Critical success factors for soil remediation policy: Ametaanalytic comparison of Dutch experiences, Z. Umweltpolitik Umweltrecht, 1, 81-98, 2000.

Nijkamp, P., P. Rietveld, and L. Spierdijk, Classification techniques in quantitative comparative research: A meta-comparison, in Spatial Economic Science, New Frontiers in Theory and Methodology, edited by A. Reggiani, pp. 102-124, Springer-Verlag, New York, 2000.

NIPO, Het Amsterdamse watergebruik thuis, Amsterdam, 1997.

Organization for Economic Cooperative Development (OECD), Water subsidies and the environment, Paris, 1997.

Organization for Economic Cooperative Development (OECD), Pricing of water services in OECD countries, update, Paris, 1998.

Pawlak, Z., Rough Sets, Kluwer Acad., Norewll, Mass., 1991.

Perman, R., Y. Ma, J. M. McGilvery, and M. Common, Natural Resource and Environmental Economics, 2nd ed., Pearson Educ., New York, 1996.

Renwick, M. E., An econometric model of household water demand with endogenous technological change under demand side management policies, Ph.D. thesis, Stanford Univ., Stanford, Calif., 1996.

Ruys, P. H. M., R. van den Brink, andR. Semenov, Values and governance structure, working paper, Tilburg Univ., Tilburg, Netherlands, 2000.

Slowinski, R., Intelligent Decision Support: Handbook of Applications and Advances of Rough Set Theory, Kluwer Acad., Norwell, Mass., 1991.

Tal, A., Case study "Sustainable Water Use in Tel-Aviv," Interdisciplinairy Cent. for Technol. Anal. in Forecasting, Tel Aviv Univ., Tel Aviv, 2000. van den Bergh, J. C. J. M. (Ed.), Handbook of Environmental and Resource Economics, Edward Elgar, Cheltenham, UK, 1999.

van den Bergh, J. C. J. M., K. J. Button, P. Nijkamp, and G. C. Pepping, Meta-Analysis in Environmental Economics, Kluwer Acad., Norwell, Mass., 1997.

VEWIN/Anderson Consulting, Water in Zicht, Benchmarking in the Water Sector (in Dutch), Rijswijk, Netherlands, 1999.

Young, R. A., and R. B. Haveman, Economics of water resources: A survey, in Handbook of Natural and Resource Economics, vol. II, edited by A. V. Kneese and J. L. Sweeney, pp. 465-529, Elsevier Sci., New York, 1985.

J. Dalhuisen and P. Nijkamp, Free University and Tinbergen Institute, Department of Spatial Economics, MASTER-point, De Boelelaan 1105, 1081 HV Amsterdam, Netherlands. (jdalhuisen@feweb.vu.nl) 